\title{
REVERSIBLE HYPERINTENSE DENTATE LESIONS
}

\author{
O. P. Lekhra, Sonali Jain, A. Maheshwari, Y. Rathore
}
1. Associate Professor. Department of Neurology, Sri Aurobindo Medical College and Post Graduate Institute, Indore.
2. Assistant Professor. Department of Radiology, Sri Aurobindo Medical College and Post Graduate Institute, Indore.
3. Senior Resident. Department of Neurology, Sri Aurobindo Medical College and Post Graduate Institute, Indore.
4. Sr.Physiotherapist. Department of Neurology, Sri Aurobindo Medical College and Post Graduate Institute, Indore.

\section{CORRESPONDING AUTHOR:}

Dr. O.P.Lekhra,

Associate Professor,

Department of Neurology,

Sri Aurobindo Medical College and Post Graduate Institute.

Indore-Ujjain State Highway,

Near MR 10 Crossing, INDORE (MP).

E-mail: olekhra@yahoo.com

INTRODUCTION: A non-hypertensive and non diabetic $30 \mathrm{yr}$ old female presented with tingling and numbness in both lower limbs over 15 days. She also had difficulty in speaking and walking for 4 days .There was no history of headache/vomitting/double vision. She was not on any drugs/ treatment. She does give history some occupational exposure for last few months as she had been working in agricultural industry which dealt with pesticides and organic solvents.

KEY WORDS: dentate nucleus ,hyperintense lesions,solvents

CASE HISTORY: On examination her vitals were stable.She had a BP 120/80 mm Hg Pulse $66 / \mathrm{min}$.She was conscious and oriented well. No meningeal signs . Neurological examination showed normal eye movements intact, Fundus -normal, dysarthia ,Motor power 5/5, dysmetria on finger-to-nose examination, and an ataxic wide-based gait. pendular knee jerk elicitable,plantar flexor. Investigation revealed $\mathrm{Hb} 10$ gm \%, TLC-7400 P 73\% L-22\% E-2\% E$3 \%$ platelet count-1.62 lacs/cmm, ESR $16 \mathrm{~mm} / \mathrm{hr}$. BUN $18 \mathrm{mg} / \mathrm{dl}$ serum creatinine- $0.83 \mathrm{mg} / \mathrm{dl}$, Serum vitamin B12 level- $711 \mathrm{pgm} / \mathrm{ml}$ thyroid profile -normal, Serum vitamin E levels -5.58 micro/ml, serum cholinesterase level-6555 u/L, CSF-unremarkable. Nerve conduction studies suggestive of symmetric mild sensory-motor neuropathy. MRI Brain revealed hyperintense lesions on bilateral dentate nucleus in T2W (Fig 1a) and FLAIR sequence(Fig 1b) .Diffusion weighted images were negative and ADC was normal for the patient. Patient was managed with symptomatic treatment and advised to stay away from the working place. Patient improved remarkably and repeat MRI FLAIR sequence (Fig-2)after a month revealed complete resolution of the lesions previously described as compared to Fig $(1 \mathrm{a}, 1 \mathrm{~b})$.

DISCUSSION: The patient's clinical course and the topography and resolution of her MRI abnormalities suggest that this condition is an energy deprivation syndrome (EDs) ${ }^{1}$. Energy deprivation syndrome are disorders with diverse etiologies i.e. toxic, genetic and nutritional. EDSs share a characteristic anatomic distribution of abnormalities with preferential damage to 
periventricular, cerebellar and brainstem areas ${ }^{5}$. These areas appear to be selectively vulnerable to metabolic-energy derailment ${ }^{1}$. Well known nutritional and genetic EDs are Wernicke's encephalopathy and Leigh'disease .The exact mechanism of this central nervous system toxicity is proposed to be related to the disruption of enzymes involved in metabolic pathways responsible for the generation of energy ${ }^{2}$. Commonest EDs is that of metronidazole induced MR imaging findings of bilateral hyperintense dentate lesions .But with no history of metronidazole in our case this seems unlikely.Other differential diagnosis of hyperintense dentate lesions remain as methyl bromide intoxication, maple syrup disease,multiple sclerosis and Wernicke encephalopathy3,4.Classically in Wernicke encephalopathy prominent involvement of inferior colliculi and periaqueductal area are seen in diffusion weighted images(DWI). Absence of pericallosal and braintem lesions and visual sparing suggest less likelihood of demyelinating illness. Patient started improving in the hospital admission after 45 days only as she was staying away from the work. Repeat MRI after a month showed reversal of the dentate lesions after a month confirming the assumption of organic solvent around the working area as the aetiological factor. As she was working in a industry where agricultural insecticides were manufactured. Organic solvents are frequently used in these industries and the review of the literature suggests that similar cases series have been described by Panda et $\mathrm{al}^{5}$ and Suwanlaong et $\mathrm{al}^{6}$.It is stressed upon that bilateral hyperintense symmetrical lesions of bilateral dentate nuclei of the cerebellum dictum must be rule out Wernicke encephalopathy then only suspect organic toxins in the differential diagnosis 6 .

\section{REFERENCES:}

1. CavanaghJ B.Methyl bromide intoxication and energy deprivation syndromes.Neuropathol Appl Neurobiol 1992;18:578-8.

2. Hyakudo T,Hori H,Tanaka I,Igisu H.Inhibition of creatine kinase activity in rat brain by methy bromide gas.Inhalation Toxicol 2001;13:659-69

3. Geyer HL,Schaumburg HH,Herskovitz S.Methyl bromide intoxication causes reversible symmetric brainstem and cerebellar MRI lesions.Neurology 2000;64(7):1279-81.

4. Ahmed A,Loes DJ,Bressler EL. Reversible resonance imaging findings in metronidazole induced encephalopathy.Neurology1995;45:588-89

5. Panda AK, Dung Dung AA,Mehta VJ Kushwaha S.Sensory neuropathy ,cataract and bilateral dentate nucleus hyperintensity in industrial solvent toxicity : a rare clinical and neuroimaging correlation .I J of Med.Specialities 2012;3(2):224-25

6. Suwanlaong K,Phanthumchinda K.Neurological manifestation of methy bromide intoxication. J Med Assoc Thai 2008;91(3):421-26 


\section{CLINICAL IMAGE}

Fig 1a T2w images of brain showing symmetrical areas of hyperintensities in the bilateral cerebellar dentate nuclei.

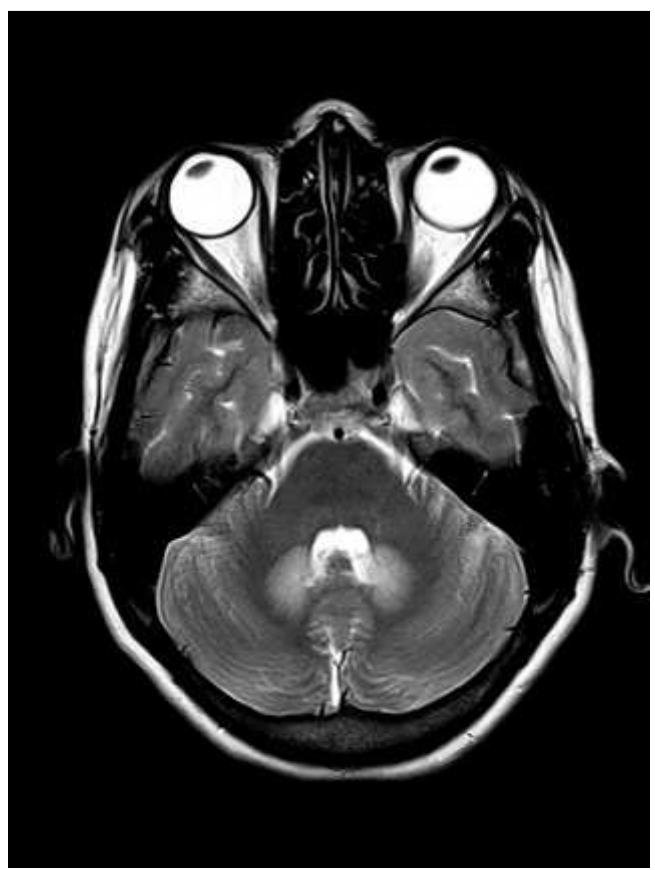

Fig 1b FLAIR images of brain showing symmetrical areas of hyperintensities in the bilateral cerebellar dentate nuclei

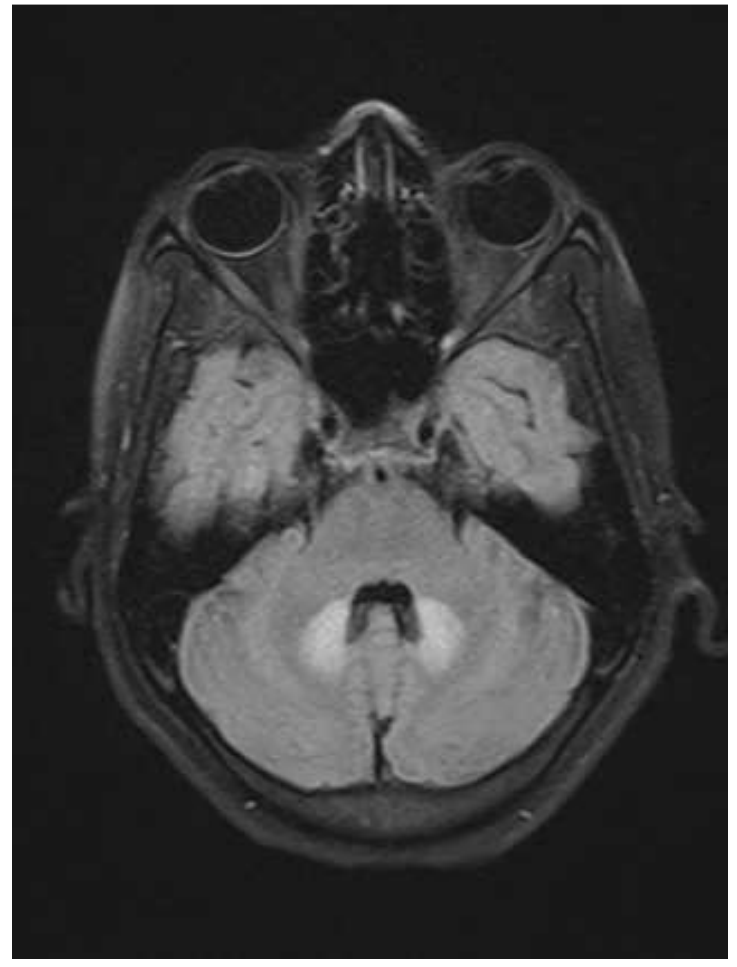


Fig 2 FLAIR images showing resolution of the abnormal hyperintense signals in the bilateral dentate nuclei as noted in the Fig $1 \mathrm{a}$ and1b

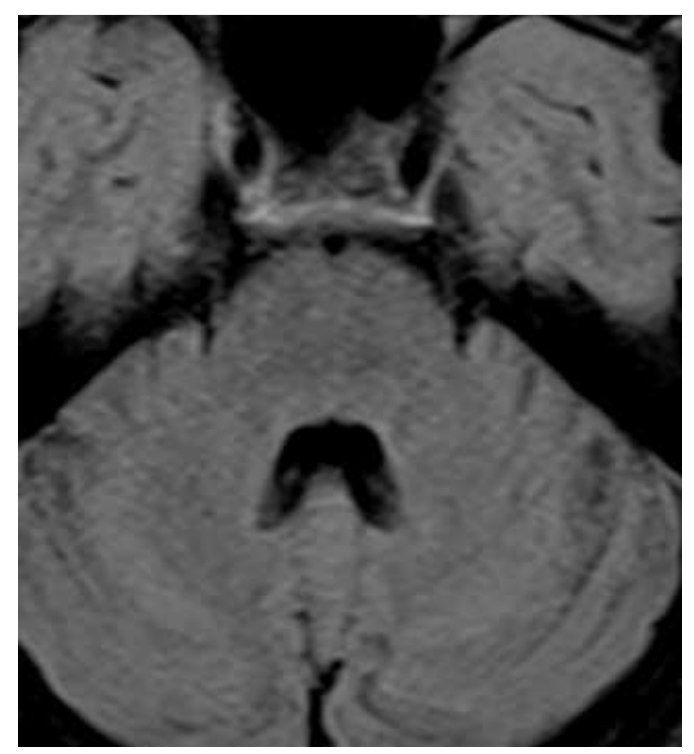

